\title{
The Relationship Between the Risk of Prostate Cancer and Second to Fourth Digit Ratio
}

\author{
(D) Tuncay Toprak, (D) Ayhan Verit \\ Fatih Sultan Mehmet Training and Research Hospital, Clinic of Urology, Istanbul, Turkey
}

\begin{abstract}
Objective: The second to fourth digit ratio is inversely related to prenatal androgen exposure, which may be a risk factor for several androgendependent diseases. One of these diseases is prostate cancer (PCa). Genes that play a role in the development of the fingers also play a role in the etiology of PCa. In this study, we aimed to evaluate whether there is a relationship between digit ratio and PCa.

Materials and Methods: The files of 45 patients diagnosed with PCa between 2016-2019 were reviewed retrospectively. Patients were called and invited to the hospital for digit measurement. Age-matched, 45 patients who were admitted to the outpatient clinic due to renal stones or renal cysts were included as a control group. Finger lengths were measured by the distance from the proximal crease to the tip, two times by a single observer, using a digital caliper, and the averages were recorded. Second to fourth digit ratios were calculated separately for right and left hand, and the groups were compared for variables.

Results: The mean age of patients with PCa was $62.9 \pm 7.2$ years, and the mean age of control group was $64.3 \pm 7.3$ years. The mean PSA level was $8.27 \pm 3.3 \mathrm{ng} / \mathrm{mL}$ and $1.39 \pm 0.63 \mathrm{ng} / \mathrm{dL}$ in study and control group, respectively. The mean digit ratios for right and left hand were $0.96 \pm 0.03$, $0,99 \pm 0.03(p<0.001)$ and $0.95 \pm 0.03,0.98 \pm 0.03(p=0.003)$ for study and control groups, respectively.

Conclusion: Men with PCa have a lower second to fourth digit ratio than healthy individuals. Therefore, the second to fourth digit ratio, which is indicative of prenatal androgen exposure, can be used as a marker of PCa risk.
\end{abstract}

Keywords: Androgens, digit ratio, prostate cancer

\section{Introduction}

Prostate cancer (PCa) is the most common malignancy in men (1). Although the etiology is not known, age, family history, ethnicity, and androgen exposure are known to pose a risk for the development of PCa (2). On the other hand, there are several markers indicating prenatal androgen exposure. One of these is the $2^{\text {nd }}$ to $4^{\text {th }}$ digit ratio (2D:4D). Low 2D:4D ratio indicates high prenatal androgenic exposure (3). Intrauterine hormones have a direct effect on the differentiation of fingers. There are studies showing a significant difference between female and male finger ratios $(4,5)$. Furthermore, studies have shown that men and women with congenital adrenal hyperplasia have a shorter digit ratio than controls $(6,7)$. Some of the genes that determine the ratio of fingers also play a role in carcinogenesis (8). In this context, the 2D:4D finger ratio has been associated with cancers such as gastric (8) and breast cancer (9), especially PCa $(10,11)$. Therefore, if the 2D:4D finger ratio is associated with the activation of these genes, it may act as a marker in carcinogenic events. Some studies have reported that a low 2D:4D ratio, in other words, high prenatal androgenic exposure, is associated with an increased risk of PCa $(10,11)$, and some have further reported that it is associated with the severity of PCa (12). The relationship between PCa and the 2D:4D digit ratio is mainly due to the simultaneous activation of genes such as androgen receptor $(A R)$ genes and Homeobox (HOX), involved in finger ratio and PCa development (10). Also, early hormonal exposure plays a role in the etiology of many cancers (13). Among these, PCa is also important because it is hormone-dependent (14). The natural course of $\mathrm{PCa}$ is challenging to predict. Some have an asymptomatic course, while others may be aggressive. Better classification of patients will help us in terms of disease management. The researchers suggest that the 2D:4D finger ratio can be used as

Cite this article as: Toprak T, Verit A. The Relationship Between the Risk of Prostate Cancer and Second to Fourth Digit Ratio. Bull Urooncol 2020;19(1):31-34

Address for Correspondence: Tuncay Toprak, Fatih Sultan Mehmet Training and Research Hospital, Clinic of Urology, İstanbul, Turkey E-mail: drtuncay55@hotmail.com ORCID-ID: orcid.org/0000-0003-1348-5273 Received: 08.12.2019 Accepted: 09.12.2019 
a marker in diseases associated with early androgenic exposure (15).

Therefore, this study aimed to investigate whether there is a relationship between 2D:4D digit ratio and PCa.

\section{Materials and Methods}

This case-control study was approved by Fatih Sultan Mehmet Training and Research Hospital Ethics Committee (decision no: FSM EAH-KAEK 2019/95), and each patient included in the study signed informed consent form. Patients who admitted to our urology outpatient clinic between 2016 and 2019 and had a diagnosis of PCa were included in the study. The cases were called and invited to the hospital for digit measurements. Patients with metastatic PCa, hormonal disorders, history of fractures on the fingers, or who underwent hormonal therapy were excluded from the study. Age-matched patients who were admitted to the outpatient clinic due to renal stones or renal cysts and had a PSA level $\leq 2.5 \mathrm{ng} / \mathrm{mL}$ were included as a control group. There were 45 patients in each group. Finger lengths were measured by the distance from the proximal crease to the tip two times by a single observer using a digital caliper as in the study of Kumar et al. (16), and the averages were recorded. To calculate the 2D:4D ratio, the length of the $2^{\text {nd }}$ finger was divided by the length of the $4^{\text {th }}$ finger.

\section{Statistical Analysis}

IBM SPSS 22 program was used for statistical analysis. When evaluating the study data, the normality of the parameters was evaluated with the Shapiro-Wilk test. Descriptive statistics were used to describe demographic and anthropometric characteristics of the patients. The mean \pm SD and median were determined for variables with normal and abnormal distribution, respectively. Studen's t-test and Mann-Whitney $U$ test were used for the comparison of parameters with the normal and abnormal distribution. Significance was evaluated at $\mathrm{p}<0.05$.

\section{Results}

The study was conducted with a total of 90 patients aged between 44 and 78 years. The mean age of 45 patients with PCa was $62.9 \pm 7.2$ years, and the mean age of 45 agematched control patients was $64.3 \pm 7.3$ years Table 1 shows the comparison of demographic characteristics and 2D:4D ratio among Pca and control groups. There was no statistically significant difference in terms of age and prostate volume. There was no correlation between prostate volumes and digit ratios ( $r=-.082, p=0.44$ for right $2 \mathrm{D}: 4 \mathrm{D}$ and $\mathrm{r}=-.010, \mathrm{p}=0.34$ for left 2D:4D). The patients with $P C$ a had significantly higher PSA levels than controls. Men with PCa had significantly lower right (R2D:4D) and left (L2D:4D) hand digit ratio than controls $(p<0.001$ and $p=0.003)$, respectively.

\section{Discussion}

Evaluating the prenatal hormonal environment can be achieved by invasive procedures such as amniotic fluid sampling or fetal blood collection. Therefore, indicators of prenatal hormonal exposure, such as the 2D:4D finger ratio, can be useful in terms of diseases that may be encountered later in life. The 2D:4D finger ratio has attracted interest in the scientific world in terms of its prenatal hormonal activity and its ability to shed light on the future effects of this condition (17). Recently, the relationship between finger ratio and PCa has been investigated. Studies have shown that finger ratio may be an estimator of the presence of PCa $(10,11,18)$. In contrast, the Melbourne Collaborative Cohort Study found no significant relationship between the risk of PCa and 2D:4D digit ratio (19). However, in patients who were diagnosed with PCa before the age of 60, a slight inverse relationship was observed between the risk of PCa and 2D:4D digit ratio in this study. Therefore, they concluded that the finger ratio might be a potential marker, especially in this age group.

The co-activation of $A R$ and HOX genes in the development of finger and PCa has shown that the 2D:4D finger ratio is a marker linking these two conditions (10). HOX genes regulate the basic aspects of morphogenesis, embryogenesis, and cell differentiation and have been shown to be deregulated in a wide variety of malignancies $(20,21)$. AR genes are involved in finger development, and finger four has more intense $A R$ activity than finger two. Therefore, activation of the $A R$ genes leads to the growth of the fourth finger, which plays a fundamental role in determining the 2D:4D finger ratio (22). It is also known that androgens affect the pathogenesis of $\mathrm{PCa}$ (23). Moreover, polymorphisms in the AR gene can lead to resistance to hormone therapy in $\mathrm{PCa}$ (24). In our study, the 2D:4D ratio was found to be significantly lower in men with PCA than in men without PCA. This finding was consistent with other studies $(3,10,11,19)$. In our study, we evaluated the finger ratios of both hands together, and the finger ratio of both hands was statistically low in the patients with PCa.

\begin{tabular}{|c|c|c|c|c|c|}
\hline & \multicolumn{2}{|l|}{ PCa $(n=45)$} & \multicolumn{2}{|c|}{ Control $(n=45)$} & \multirow[t]{2}{*}{$p$} \\
\hline & Mean \pm SD & Median (range) & Mean \pm SD & Median (range) & \\
\hline PSA (ng/dL) ${ }^{1}$ & $8.27 \pm 3.3$ & $8.2(1.5-17)$ & $1.39 \pm 0.63$ & $1.34(0.4-2.5)$ & $<0.001^{*}$ \\
\hline PV $(g r)^{2}$ & $45 \pm 12.46$ & $44(20-90)$ & $40.7 \pm 19.18$ & $43(13-72)$ & 0.55 \\
\hline
\end{tabular}


In contrast to our study, many studies have looked at only the $2 \mathrm{D}: 4 \mathrm{D}$ ratio of the right hand $(10,11,12,23)$, considering that the 2D:4D ratio of the right hand shows prenatal androgenic exposure better than the left hand (25). However, other studies examining the relationship between the 2D:4D ratio and cancer found significant relationships with the left hand $(8,9,26)$. Therefore, the importance of the ratio of fingers in both hands was emphasized in these studies. As expected, patients with PCa had higher PSA values than patients without PCa. However, its effect on the digit ratio is unknown. Prostate volumes and finger ratios were not correlated. This finding may be related to the similarity of the prostate volumes of the two groups.

In our study, we could not evaluate the relationship between PCa aggressiveness and 2D:4D finger ratio due to the absence of patients with Gleason scores as high as Gleason 9,10, and the majority of patients had a Gleason score of 6 . Already, there are not many studies evaluating PCa aggressiveness and 2D:4D ratio in the literature, and the results are contradictory. Waters et al. (17) found no association between Gleason score and 2D:4D digit ratio, whereas $\mathrm{Oh}$ et al. (27) found that individuals with a Gleason score of 9 and above had a smaller 2D:4D digit ratio. This inconsistency can be attributed to the unpredictability of natural PCa history.

\section{Study Limitations}

Firstly, testosterone levels were not predicted to make an additional contribution because the 2D:4D finger ratio was considered to be stable in adulthood. So, testosterone levels of the individuals in our study were not evaluated. Secondly, individuals were not questioned about their work or job. The work of individuals in daily life may affect the development of hands and fingers. However, it was impossible to evaluate.

\section{Conclusions}

Our study supports the hypothesis that low 2D:4D finger ratio may be a predictor of the presence of PCa. It can be concluded that increased exposure to testosterone in utero may increase the risk of PCa in later life. Further studies are needed to make the 2D:4D ratio a predictive marker for screening developing PCa risk.

\section{Acknowledgements}

Publication: The results of the study were not published in full or in part in form of abstracts.

Contribution: There is an other contributor who may not be listed as authors: Umut Arslan, Fatih Sultan Mehmet Training and Research Hospital, Clinic of Urology, İstanbul.

Conflict of Interest: No conflict of interest was declared by the authors.

Financial Disclosure: The authors declared that this study received no financial support.

\section{Ethics}

Ethics Committee Approval: This case-control study was approved by Fatih Sultan Mehmet Training and Research Hospital Ethics Committee (number: FSM EAH-KAEK 2019/95).
Informed Consent: Informed consent was obtained from all individual participants included in the study.

Peer-review: Externally peer-reviewed.

\section{Authorship Contributions}

Concept: A.V., Design: A.V., Data Collection or Processing: T.T., Analysis or Interpretation: T.T., Literature Search: A.V., T.T., Writing: T.T.

\section{References}

1. Attard G, Parker C, Eeles RA, et al. Prostate cancer. Lancet 2016;387:70-82

2. Damber JE, Aus G. Prostate cancer. Lancet 2008;371:1710-1721.

3. Mendes PH, Martelli DR, de Melo Costa S, et al. Comparison of digit ratio (2D:4D) between Brazilian men with and without prostate cancer. Prostate Cancer Prostatic Dis 2016;19:107-110.

4. Peters M, Tan U, Kang Y, Teixeira L, Mandal M. Sex-specific fingerlength patterns linked to behavioral variables: consistency across various human populations. Percept Mot Skills 2002;94:171-181.

5. Manning JT, Barley L, Walton J, et al. The 2nd:4th digit ratio, sexual dimorphism, population differences, and reproductive success. evidence for sexually antagonistic genes? Evol Hum Behav 2000;21:163-183.

6. Brown WM, Hines M, Fane BA, Breedlove SM. Masculinized finger length patterns in human males and females with congenital adrenal hyperplasia. Horm Behav 2002;42:380-386.

7. Okten A, Kalyoncu M, Yaris N. The ratio of second- and fourth-digit lengths and congenital adrenal hyperplasia due to 21-hydroxylase deficiency. Early Hum Dev 2002;70:47-54.

8. Nicolas Hopp R, de Souza Lima NC, Filho JL, et al. Digit ratio (2D:4D) is associated with gastric cancer. Early Hum Dev 2013; 89:327-329.

9. Muller DC, Baglietto L, Manning JT, et al. Second to fourth digit ratio (2D:4D), breast cancer risk factors, and breast cancer risk: a prospective cohort study. Br J Cancer 2012;107:1631-1636.

10. Jung $\mathrm{H}$, Kim KH, Yoon SJ, Kim TB. Second to fourth digit ratio: a predictor of prostate-specific antigen level and the presence of prostate cancer. BJU Int 2011;107:591-596.

11. Rahman AA, Lophatananon A, Stewart-Brown $S$, et al. Hand pattern indicates prostate cancer risk. Br J Cancer 2011; 104:175-177.

12. Oh JK, Kim KH, Jung $H$, Yoon SJ, Kim TB. Second to fourth digit ratio: its relationship with core cancer volume and Gleason score in prostate biopsy. Int Braz J Urol 2012;38:611-619.

13. Potischman N, Troisi R, Thadhani R, et al. Pregnancy hormone concentrations across ethnic groups: implications for later cancer risk. Cancer Epidemiol Biomarkers Prev 2005; 14:1514-1520.

14. Endogenous Hormones and Prostate Cancer Collaborative Group, Roddam AW, Allen NE, Appleby P, Key TJ. Endogenous sex hormones and prostate cancer: a collaborative analysis of 18 prospective studies. J Natl Cancer Inst 2008;100:170-183.

15. Ronalds G, Phillips DI, Godfrey KM, Manning JT. The ratio of second to fourth digit lengths: a marker of impaired fetal growth? Early Hum Dev 2002;68:21-26.

16. Kumar S, Voracek M, Singh M. Differential placing of flexion creases contributes to sex differences in the second-to-fourth digit ratio (2D: 4D). Front Endocrinol (Lausanne) 2019;10:537.

17. Waters M, Rebholz C, Wood B, et al. Second to fourth digit ratio and prostate cancer severity. Prostate Cancer Prostatic Dis 2013;16:107.

18. Peters N, Armstrong K. Racial differences in prostate cancer treatment outcomes: a systematic review. Cancer Nurs 2005;28:108-118.

19. Muller DC, Giles GG, Manning JT, Hopper JL, English DR, Severi G. Second to fourth digit ratio (2D:4D) and prostate cancer risk in the Melbourne Collaborative Cohort Study. $\mathrm{Br}$ J Cancer 2011; 105:438-440. 
20. Nunes FD, de Almeida FC, Tucci R, de Sousa SC. Homeobox genes: a molecular link between development and cancer. Pesqui Odontol Bras 2003;17:94-98.

21. Takahashi Y, Hamada J, Murakawa K, et al. Expression profiles of 39 HOX genes in normal human adult organs and anaplastic thyroid cancer cell lines by quantitative real-time RT-PCR system. Exp Cell Res 2004;293:144-153.

22. Zheng Z, Cohn MJ. Developmental basis of sexually dimorphic digit ratios. Proc Natl Acad Sci U S A 2011;108:16289-16294.

23. Nelson WG, De Marzo AM, Isaacs WB. Prostate cancer. N Engl J Med 2003;349:366-381.
24. Taplin ME, Bubley G], Ko YJ, et al. Selection for androgen receptor mutations in prostate cancers treated with androgen antagonist. Cancer Res 1999;59:2511-2515.

25. Honekopp J, Watson S. Meta-analysis of digit ratio 2D:4D shows greater sex difference in the right hand. Am J Hum Biol 2010;22:619-630.

26. Hopp R, Lima Filho N, JLF Filho JJ. Digit ratio is associated with colorectal cancer. J Gastrointest Dig Syst 2015;5:2.

27. Oh JK, Kim KH, Jung H, Yoon SJ, Kim TB. Second to fourth digit ratio: its relationship with core cancer volume and Gleason score in prostate biopsy. Int Braz J Urol 2012;38:611-619. 